voluntary contributions from Governments, and it was not until 1957 that the United States changed its policy and contributed 5 million dollars to the Account. The British Government maintained the view that such an eradication campaign should be financed through the regular budget of the World Health Organization (to which the United Kingdom contributes 7 per cent), and at the General Assembly of the Organization in New Delhi in February the United Kingdom supported a scheme which would put any shortage in voluntary contributions immediately on the regular budget. The administrative and operational costs of more than 600,000 dollars had already fallen on the regular budget in 1961; an additional 2 million dollars would fall on it for 1962 , double this for 1963 ; and the whole 6 million dollars in 1964, an increase of more than 20 per cent in the 1962 budget of 23.6 million dollars. This would involve further contributions from the United Kingdom of 140,000 dollars in $1962,280,000$ dollars in 1963 and 420,000 dollars in 1964. Under the scheme adopted, which gives credits to the member countries carrying out malaria eradication campaigns and have low per capita incomes, a group of about 30 countries with relatively large per capita incomes will share the burden which in the past was borne by a few volunteers but mainly by the United States, which contributed about 90 per cent. Miss Pitt said that in the future the Director-General of the World Health Organization would be able to plan more effectively, since he could rely on the resources of his regular budget, and she also emphasized the substantial contribution from Britain on the technical side in research and training facilities.

\section{Public Health Nursing}

THE nursing profession throughout the world is faced with a severe shortage of recruits to its ranks. In the developed countries an increased burden is being placed on its shoulders by the growing com. plexity of medical services, treatment and equipment; the demand for nurses is rising at a time when the supply is falling off as a result of the availability elsewhere of better-paid jobs in easier working conditions. In the less-developed countries the demand for nurses is enormous; but the supply is restricted by unwillingness to allow women to become nurses, by the low status of nursing, and, above all, by the absence of the money to pay them. This crisis in the nursing profession has led to a re-appraisal of the functions of nurses and to various attempts to use auxiliary workers for the less-essential tasks of nursing, thus freeing nurses for the more-essential. A volume in the series of Public Health Papers by the World Health Organization contains a collection of papers by nursing and other experts from all parts of the world, who discuss the training and functions of public health nurses, the basic curriculum and the changes that the new situation is bringing about and should bring about in it, the importance of team work, the value of knowledge of administration, the role of the auxiliary worker, and the fresh approach now required of public health nurses (No. 4 : Aspects of Public Health Nursing. Pp. 185. 5 Swiss francs; $8 s .6 d . ; 1.75$ dollars; by various authors. (Geneva: World Health Organization; London: H.M.S.O.) 1961). There are several contributions describing how countries-such as Brazil, France and the U.S.S.R.-have dealt with the problem of the auxiliary worker. A final paper discusses the difficulties met by international nurses working in other countries with strange cultures, different standards and attitudes.

\section{Rural Research in C.S.I.R.O.}

Among the many periodicals that nowadays come to our libraries, those of the Commonwealth Seientific and Industrial Research Organization of Australia have for long maintained a high value, and Rural Research in C.S.I.R.O. has for some years now kept agriculturalists well informed about the progress of agricultural research in Australia. The issue for December 1960 (No. 34, obtainable from the Agricultural Liaison Section of the Commonwealth Seientific and Industrial Research Organization, 314 Albert St., East Melbourne, C.2, Victoria) discusses the experimental work being carried out in Queensland on the rearing of cattle in a tropical environment, and the characteristics of the coats of the cattle in relation to this. Other articles deal with: research on the wool of sheep; sheep fluorosis; improved cobalt treatment of sheep; the use of the electron microscope in agricultural research (illustrated by striking photographs); soils and sulphur deficiency in soils; and new techniques which can extend the storage life of apples.

\section{Bering Strait Dam}

P. M. BonIsov has outlined a project, in the October (1959) issue of Literaturnaya Gazeta, of a $90 \mathrm{~km}$. long dam across the Bering Strait equipped with powerful pumps pumping cold Arctic Ocean water into the Pacific Ocean at the rate of $500 \mathrm{~km} .^{3}$ in 24 hours. Such a project, according to Borisov, would increase the flow of warm Atlantic Ocean water into the Arctic Ocean and change the climate of the Arctic regions. This project is criticized by D. A. Drogaitzev (Priroda, 6, 35; 1960), who, on the basis of detailed calculations, argues that such a project would displace the locus of Atlantic Ocean cyclones to the region of the Barentz Sea. Such a displacement would certainly change the climate of Northern Europe and Western Siberia, but this change will produce colder winters and hotter summers and will lead to the displacement of the desert belt from the region of North Africa and Central Asia to the north of Europe. At the same time the northern Pacifio region will also undergo a climatic deterioration.

\section{The Manchester Museum}

IN the annual report of the Manchester Museum for 1959-60, special mention is naturally made of three additions to the exhibition space. The special Japanese gallery to house the Lloyd collections has been completed, a coin room has been provided, and certain re-allocations with the University have made possible botanical offices and laboratories and the re-organization of the great herbarium. Two outstanding purchases were made during the year-two Celtic gold bracelets dug up in $\mathbf{1 8 2 9}$ at Malpas in Cheshire and an Iron Age gold necklace found at Burnley in 1801. By the aid of various funds and a subscription list it was possible to purchase these three objects. A bequest of great importance was the Leslie Armstrong collection excavated from Pin Hole Cave, Derbyshire. It comprises about 14,500 bones, bone flakes, antlers and teeth. The report closes with an impressive list of publications by the staff.

The Birmingham Museum of Science and Industry

Birmingham City Council has approved the rebuilding of the Museum of Science and Industry. 